\title{
Screening for late neonatal vitamin K deficiency by acarboxyprothrombin in dried blood spots
}

\author{
K MOTOHARA, F ENDO, AND I MATSUDA \\ Department of Pediatrics, Kumamoto University Medical School, Japan
}

SUMMARY Acarboxyprothrombin (protein induced by vitamin $\mathrm{K}$ absence or antagonist-II (PIVKA-II)) concentrations in dried blood spots were determined in 19029 infants at about 1 month of age as an indicator of vitamin $\mathrm{K}$ deficiency. We observed 51 cases with raised blood concentrations of PIVKA-II $(>4 \mathrm{AU} / \mathrm{ml})$, nine of whom showed very high concentrations $(>20$ $\mathrm{AU} / \mathrm{ml})$.

For infants who did not receive vitamin $\mathrm{K}$ prophylaxis at birth, the incidence of the PIVKA-II test yielding positive results was significantly higher in those solely breast fed $(0.51 \%)$ compared with those fed formula milk $(0 \cdot 18 \%)$. Among solely breast fed infants, the incidence of a very high result of the PIVKA-II test was $0 \cdot 14 \%$ in those who had not received vitamin K prophylaxis at birth, $0.04 \%$ in those who received $2 \mathrm{mg}$ orally, and $0.03 \%$ in those who received $2 \mathrm{mg}$ orally plus a further dose of $2-4 \mathrm{mg}$ orally at 7 days.

Thus vitamin $\mathrm{K}$ prophylaxis at birth did not completely prevent vitamin $\mathrm{K}$ deficiency at 1 month. We administered vitamin $\mathrm{K}$ therapeutically to all infants whose PIVKA-II test yielded a positive result at 1 month. Only one infant with a positive result developed late neonatal intracranial haemorrhage.

Severe intracranial haemorrhage related to vitamin $\mathrm{K}$ deficiency in infants aged 1 month may occur suddenly and lead to death or severe central nervous system dysfunction. Almost all of the affected infants who have been reported had not received vitamin $\mathrm{K}$ at birth. ${ }^{1-8}$ The American Academy of Pediatrics recommends that all newborn infants receive vitamin $K$ (a single parenteral dose of $0.5-1.0 \mathrm{mg}$ or $1.0-2.0 \mathrm{mg}$ orally). ${ }^{9}$ In Japan newborn infants are not given routine vitamin $\mathrm{K}$ prophylaxis. This might be one of the reasons for the high incidence of late neonatal vitamin $\mathrm{K}$ dependent intracranial haemorrhage in our country. This disorder occurs in one in every 4500 infants and one in every 1700 breast fed infants who are not given vitamin $\mathrm{K}$ prophylaxis. ${ }^{\prime}$

Recently, the study group of the Ministry of Health and Welfare of Japan recommended that all newborn infants should receive vitamin $\mathrm{K}$ orally, ${ }^{1}$ but intramuscular administration of the vitamin was not recommended. In this study we report a mass screening system for acarboxyprothrombin (protein induced by vitamin $\mathrm{K}$ absence or antagonist-II (PIVKA-II)) as an indicator of vitamin $\mathrm{K}$ deficiency at 1 month. PIVKA-II is a precursor of active prothrombin and converted to the active form by vitamin $\mathrm{K}$ and carboxylase. ${ }^{10}$ This study aimed to evaluate the effect of oral vitamin $\mathrm{K}$ that had been administered after birth and to detect patients with severe vitamin $\mathrm{K}$ deficiency at 1 month before symptoms occurred.

\section{Patients and methods}

Plasma PIVKA-II concentration was measured by means of an assay using a monoclonal, monospecific antibody. ${ }^{11}$ The PIVKA-II concentration in dried blood spots was determined as follows. Blood was spotted on filter paper, four discs of $6 \mathrm{~mm}$ diameter were punched out for each individual, and then the blood was eluted from the discs for one hour in $0 \cdot 3$ $\mathrm{ml}$ of phosphate buffered saline $(10 \mathrm{mM}$ phosphate

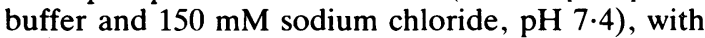
horizontal shaking. Then $100 \mu \mathrm{l}$ of the eluate was subjected to the PIVKA-II assay as described previously. ${ }^{11}$ Each measurement was performed in duplicate. The PIVKA-II concentrations determined for the same blood sample with different assay systems were compared to evaluate the reliability of the dried blood assay system. 
Monitoring of PIVKA-II concentrations by the blood spot test was carried out in 19029 young infants aged about 1 month in the Kumamoto region of Japan between April 1984 and January 1986. Measurements were made within 24 hours of receiving the samples. Roughly $90 \%$ of the breast fed infants in this area were included in this survey. The infants consisted of 11107 who were breast fed, 7157 who were both breast and formula fed (mixed fed), and 765 who were formula fed. As breast feeding is known to be a risk factor for vitamin $\mathrm{K}$ deficiency most of the women who participated in the monitoring were breast feeding their infants. The incidence of haemorrhagic disease in the first week of life among these infants was not known and infants who showed early neonatal bleeding were not excluded. Those infants allocated to receive vitamin $\mathrm{K}$ were given either $2.0 \mathrm{mg}$ orally within 24 hours of birth (one dose) or this initial dose plus 2-4 mg orally at 1 week of age (two doses). The decision to administer vitamin $\mathrm{K}$ and the manner of administration were determined by the obstetricians. The vitamin was given as vitamin $\mathrm{K}_{2}$ syrup (Kay Two Syrup (menaquinone 4, 2-methyl-3-all-transtetraprenyl-1, 4-maphthoquinone), Eisai Co Ltd, Tokyo, Japan) because vitamin $\mathrm{K}_{1}$ was unavailable as a syrup in Japan.

In Japan all infants are examined under the child health survey program at 1 month of age. At this examination we obtained informed consent from all the parents and then took blood samples from the infants by means of a heel puncture, which were then spotted onto filter paper, dried, and sent to our laboratory by post.

The cut off point for PIVKA-II on the blood spot test was set at $4.0 \mathrm{AU} / \mathrm{ml}$. One arbitrary unit (AU) corresponds to $1 \mu \mathrm{g}$ purified prothrombin. Our preliminary study suggested that in breast fed infants aged 1 month who had not received vitamin $\mathrm{K}$ prophylaxis the $\mathbf{0} \cdot \mathbf{6}$ centile for PIVKA-II might be about $4 \cdot 0 \mathrm{AU} / \mathrm{ml} .^{12}$ This cut off point was anticipated to select 10 -fold the number of infants with late onset bleeding due to vitamin $\mathrm{K}$ deficiency, based on an estimated incidence of $0.06 \% .^{1}$ When the result was above this the plasma PIVKA-II concentration and normotest activity were measured by methods previously described ${ }^{11}$ and then $5 \mathrm{mg}$ vitamin $\mathrm{K}_{2}$ given orally.

When the PIVKA-II concentration was higher than $20 \mathrm{AU} / \mathrm{ml}$ according to the blood spot test 1-2 mg vitamin $K_{2}$ was injected within six hours of the diagnosis being made. Infants with normotest activities of under $20 \%$ had a computed tomogram taken. The normotest activity reflects the total coagulant activities of factors II, VII, and $\mathrm{X} .{ }^{13}$ The normal mean (SD) normotest value in breast fed infants at 1 month of age is 71.4 $(17 \cdot 0) \%(n=218){ }^{14}$

The comparison of incidences between various groups was analysed by the $\chi^{2}$ test with Yates's correction.

\section{Results}

Measurement of PIVKA-II in dried blood spots. Figure 1 shows the correlation between PIVKA-II values on dried blood spots and those obtained by measuring PIVKA-II in plasma samples from the same subjects. Blood samples with high PIVKA-II concentrations were obtained from 27 adults receiving warfarin as it was difficult to obtain many samples from the infants with vitamin $K$ deficiency at the same time. The high correlation indicated that the dried blood method was reliable for measurement of PIVKA-II concentrations. The detection limit for blood PIVKA-II was $1 \cdot 0-32 \cdot 0 \mathrm{AU} / \mathrm{ml}$ with the dried blood method. The coefficients of variance of intra- and interassays were less than 0.06. The recovery of PIVKA-II from dried blood spots was monitored after spotting. A mean of $87.7 \%(n=27)$ of the initial PIVKA-II concentration was found at room temperature on the fifth day after the blood had been obtained.

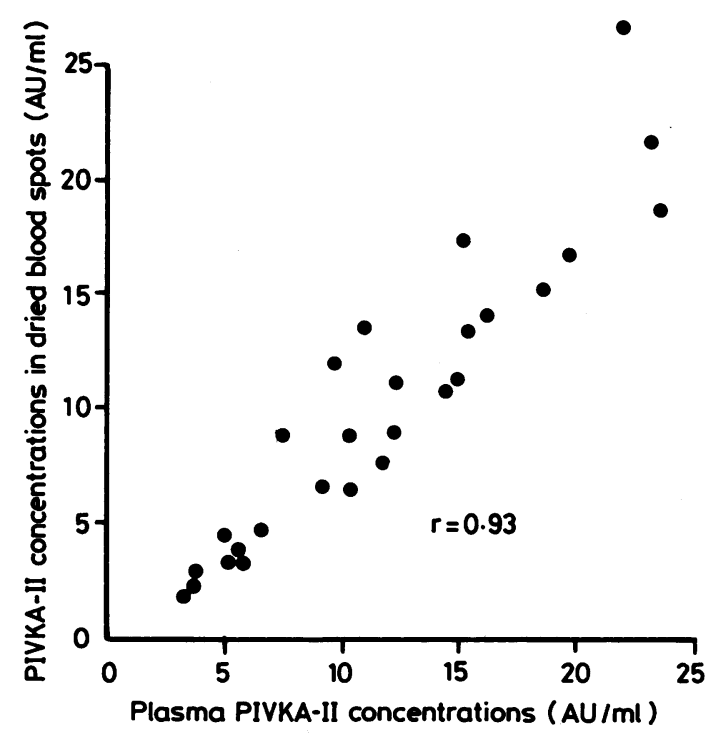

Fig. 1 Correlation between PIVKA-II concentrations in dried blood spots and in plasma samples from the same subjects. The equations for the regression lines for the PIVKA-II values for dried spots $\mathrm{v}$ those for plasma are $y=0.97 x-1.07, r=0.93, p<0.005$. 
Table 1 Infants with positive results of PIVKA-II test according to method of feeding and vitamin K prophylaxis at birth

\begin{tabular}{|c|c|c|c|c|c|c|}
\hline \multirow[t]{2}{*}{ Group } & \multirow[t]{2}{*}{ Vitamin $K$ prophylaxis } & \multirow[t]{2}{*}{ No } & \multicolumn{2}{|c|}{ PIVKA-II >4AU/ml $($ No $(\%)) \dagger$} & \multicolumn{2}{|c|}{ PIVKA-II >20 AUlml $(\text { No }(\%))^{\dagger}$} \\
\hline & & & $\begin{array}{l}\text { Solely } \\
\text { breast fed }\end{array}$ & $\begin{array}{l}\text { Mixed or } \\
\text { formula fed }\end{array}$ & $\begin{array}{l}\text { Solely } \\
\text { breast fed }\end{array}$ & $\begin{array}{l}\text { Mixed or } \\
\text { formula fed }\end{array}$ \\
\hline 1 & None & $\begin{array}{l}8346 \\
(5090)^{*}\end{array}$ & $26(0 \cdot 51)$ & $6(0 \cdot 18)$ & $7(0 \cdot 14)$ & $0(0)$ \\
\hline 2 & $2 \mathrm{mg}$ orally on day 1 & $\begin{array}{c}5169 \\
(2811)^{*}\end{array}$ & $10(0 \cdot 36)$ & $3(0 \cdot 13)$ & $1(0 \cdot 04)$ & $0(0)$ \\
\hline \multirow[t]{2}{*}{3} & $\begin{array}{l}2 \mathrm{mg} \text { orally on day } 1 \\
\text { and } 2-4 \mathrm{mg} \text { on day } 7\end{array}$ & $\begin{array}{c}5514 \\
(3206)^{*}\end{array}$ & $6(0 \cdot 19)$ & $0(0)$ & $1(0 \cdot 03)$ & $0(0)$ \\
\hline & Total & 19029 & $42(0 \cdot 38)$ & $9(0 \cdot 11)$ & $9(0.08)$ & $0(0)$ \\
\hline
\end{tabular}

*No of solely breast fed infants.

$\dagger \mathrm{AU}=$ Arbitary unit.

PIVKA-II $>4 \mathrm{AU} / \mathrm{ml}=$ Group $1 v$ group 3, $\mathrm{p}<0 \cdot 01$; group $1 v$ group 2, not significant; group 1 solely breast fed $v$ group 1 mixed or formula fed, p<0.05; total solely breast fed $v$ total mixed or formula fed, $\mathrm{p}<0 \cdot 01$.

PIVKA-II $>20 \mathrm{AU} / \mathrm{ml}$ : Total solely breast fed $v$ total mixed or formula fed, $\mathrm{p}<0.05$.

Table 2 Clinical and laboratory data of infants with very high PIVKA-II concentrations (>20 AU/ml)

\begin{tabular}{llllll}
\hline $\begin{array}{l}\text { Case } \\
\text { no }\end{array}$ & $\begin{array}{l}\text { Age } \\
\text { (days) }\end{array}$ & Sex & \multicolumn{2}{l}{ PIVKA-II concentrations } & $\begin{array}{l}\text { Normotest } \\
\text { activity (\%) }\end{array}$ \\
\cline { 5 - 6 } & & & Dried blood & Plasma & \\
\hline 1 & 31 & M & $>32 \cdot 0$ & $40 \cdot 1$ & $<10$ \\
2 & 32 & M & $>32 \cdot 0$ & $54 \cdot 4$ & $<10$ \\
3 & 36 & F & $>32 \cdot 0$ & $65 \cdot 5$ & $<10$ \\
4 & 39 & M & $>32 \cdot 0$ & ND & ND \\
5 & 31 & M & $>32 \cdot 0$ & ND & ND \\
6 & 33 & M & $>32 \cdot 0$ & $38 \cdot 0$ & $<10$ \\
7 & 31 & F & $>32 \cdot 0$ & $54 \cdot 4$ & $11 \cdot 0$ \\
8 & 37 & M & $>32 \cdot 0$ & $69 \cdot 7$ & $12 \cdot 5$ \\
9 & 35 & M & $16 \cdot 7$ & $23 \cdot 24$ & $15 \cdot 0$ \\
\hline
\end{tabular}

$\mathrm{ND}=$ Not done

All but case 9 had blood spot values above the upper detection limit $(>32 \cdot 0$ $\mathrm{AU} / \mathrm{ml})$. Case 9 was included because plasma PIVKA-II was above $20 \mathrm{AU} / \mathrm{ml}$.

Results of screening for vitamin $\mathbf{K}$ deficiency. The results of the screening survey are shown in Table 1. Fifty one cases with high PIVKA-II concentrations $(>4.0 \mathrm{AU} / \mathrm{ml})$ were found among the 19029 infants who were monitored. Of these, 42 were solely breast fed, nine mixed fed, and none solely formula fed.

For infants who did not receive vitamin K prophylaxis, the incidence of vitamin $\mathrm{K}$ deficiency was higher in those who were entirely breast fed compared with those who received formula or mixed feeds $(p<0 \cdot 05)$. When all the infants were classified into three groups according to vitamin $\mathrm{K}$ prophylaxis-group 1 (none), group 2 ( $2 \mathrm{mg}$ orally at birth), and group 3 (2 mg orally at birth and 2-4 $\mathrm{mg}$ orally at 1 week) - the incidence of vitamin $\mathrm{K}$ deficiency was higher in group 1 (32 of 8346, $0 \cdot 38 \%$ ) compared with group 3 (6 of $5514,0 \cdot 11 \%$ ) $(\mathrm{p}<0 \cdot 01)$.

All nine cases of severe vitamin $\mathrm{K}$ deficiency (PIVKA-II $>20 \mathrm{AU} / \mathrm{ml}$ ) were entirely breast fed. Seven belonged to group 1 for vitamin K prophy- laxis and one to each of the other two groups. Although the incidence of severe vitamin $\mathrm{K}$ deficiency did not differ significantly between these groups, there was a trend towards a decreasing incidence of severe vitamin $\mathrm{K}$ deficiency with increasing vitamin $\mathrm{K}$ prophylaxis (from group 1 to group 3) (Table 1).

Clinical and laboratory data. Laboratory data for the nine infants with severe vitamin $\mathrm{K}$ deficiency are shown in Table 2. After the intramuscular injection of 1-2 mg vitamin $\mathrm{K}$ normotest activities returned to normal within 24 hours and plasma PIVKA-II concentrations decreased gradually and reached normal within eight to 14 days (Fig. 2).

Only one of the 51 infants with a positive result of the PIVKA-II test had evidence of late onset haemorrhage, and that was a baby with severe vitamin $\mathrm{K}$ deficiency who had an asymptomatic small subdural haemorrhage apparent on computed tomography (Table 2, case 2). Among the other infants with severe vitamin $\mathrm{K}$ deficiency, a diagnosis of congenital bile duct atresia was later established in case 6. Other forms of hepatic dysfunction, manifest by raised serum transaminase activities, were observed in cases 2 and 4.

In the present study only one infant with a negative result of the PIVKA-II test had late onset haemorrhage (intracranial bleeding), and this occurred 21 days after the blood spot test had yielded negative results. This infant had congenital bile duct atresia.

\section{Discussion}

Direct determination of plasma vitamin K may lead to a greater understanding of the role of this vitamin ${ }^{15}$ but the direct assay is not practical for a 


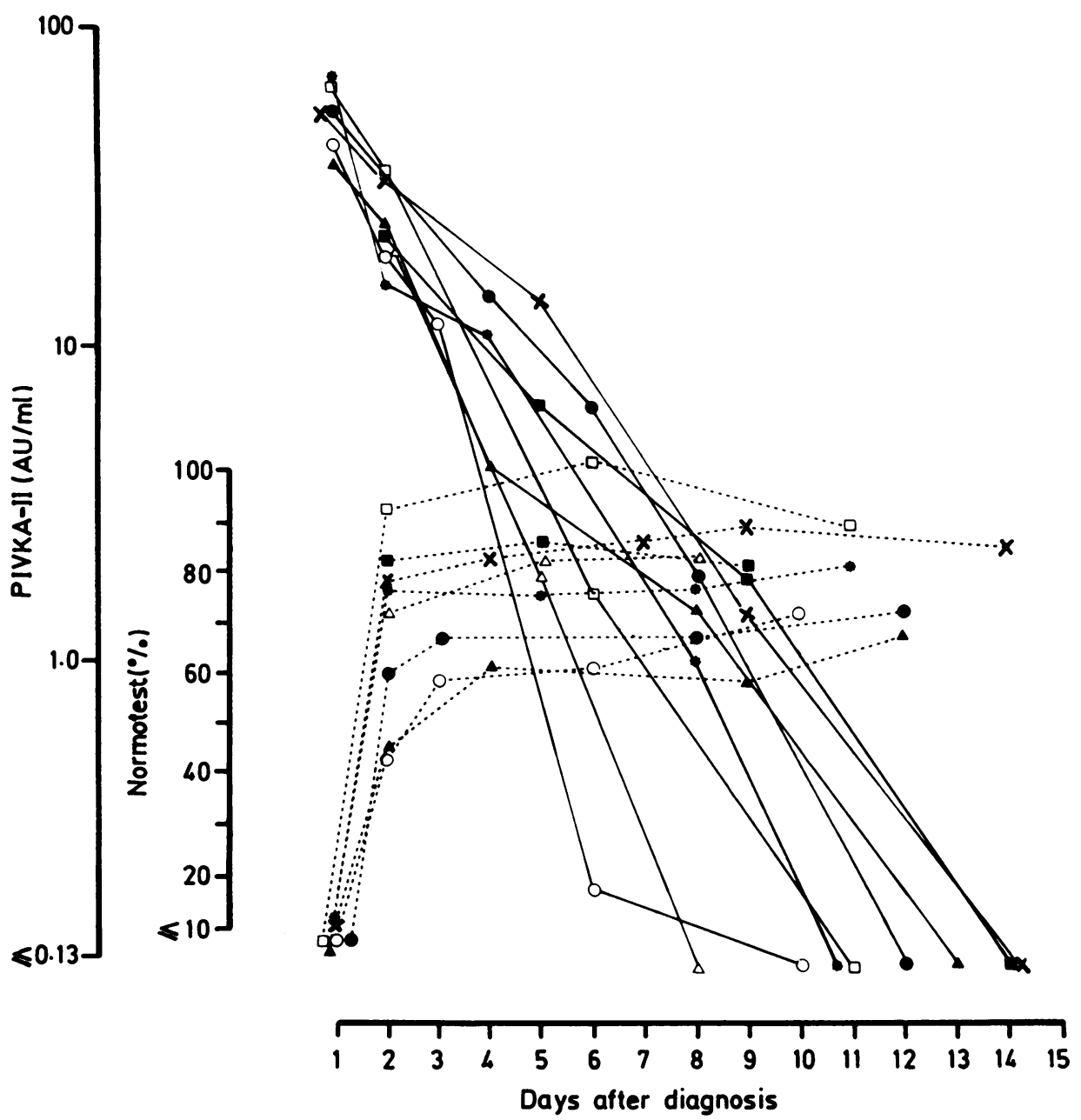

Fig. 2 Effects of intramuscular administration of vitamin $K_{2}(1-2 \mathrm{mg})$ on plasma PIVKA-II and normotest activity in infants with vitamin $K$ deficiency. The solid lines represent plasma PIVKA-II, the broken lines the normotest activity. The eight infants represented here are those with blood spot PIVKA-II concentrations $>20 \mathrm{AU} / \mathrm{ml}$. All had values above the upper limit of detection $(>32 \mathrm{AU} / \mathrm{ml})$.

hospital service. PIVKA-II occurs in peripheral blood in vitamin $\mathrm{K}$ deficiency or patients treated with warfarin but is not present in normal adults. ${ }^{10} 16-18$ Thus measurement of the plasma PIVKA-II concentration is useful for evaluating vitamin K deficiency. Previously, we measured PIVKA-II concentrations in newborn infants as an indicator of vitamin $\mathrm{K}$ deficiency and concluded that oral vitamin $\mathrm{K}$ prophylaxis at birth was effective in preventing early neonatal bleeding. ${ }^{19}$

Faced with the need for prophylaxis for all neonatal infants, physicians have been reluctant to use the usual intramuscular injection routinely in Japan. McNinch et al and Sann et al reported that serum vitamin $\mathrm{K}$ concentration increased considerably after oral administration of vitamin $\mathrm{K}(1-2 \mathrm{mg})$ and concluded that oral administration of vitamin $\mathrm{K}$ was sufficient to prevent neonatal bleeding due to vitamin $\mathrm{K}$ deficiency. ${ }^{2021}$ Oral prophylaxis with vitamin $\mathrm{K}$ in newborn infants is more economical and simpler than intramuscular prophylaxis. The oral route is most practical when routine administration is required for all newborn infants.

It is not clear at present whether oral administra- 
tion of vitamin $\mathrm{K}$ in the neonatal period is effective in preventing late onset infantile bleeding due to vitamin $\mathrm{K}$ deficiency at about 1 month of age. ${ }^{22} \mathrm{We}$ have been unable to find any published data relating to this problem. The purpose of this survey was to obtain both a scientific basis for an effective protocol for preventing vitamin $\mathrm{K}$ deficiency and a means of identifying this disease before clinical symptoms occurred. To achieve this a large number of subjects was necessary as the incidence of the disease is fairly low. We therefore developed the mass monitoring system for PIVKA-II described in this paper. The reliability of the simplified method using dried blood spots was sufficient for these purposes.

In this study the infants were divided into three groups according to vitamin $\mathrm{K}$ prophylaxis. We could then evaluate the prolonged effect of administration of vitamin $\mathrm{K}$ in the newborn period. We showed that breast feeding was a risk factor for the disease, supporting the results of retrospective surveys. ${ }^{1-8}$ The incidence of infants with a PIVKAII test that yielded positive results $(>4 \mathrm{AU} / \mathrm{ml})$ among untreated infants was higher compared with those given two doses of vitamin $\mathrm{K}$, whereas the incidences of very high PIVKA-II concentrations $(>20 \mathrm{AU} / \mathrm{ml})$ in the two treated groups were similar. We are unable to conclude at present whether or not a double dose of vitamin $\mathrm{K}$ offers more protection than a single dose. It was hoped that both neonatal bleeding and late onset infantile bleeding could be prevented with a single administration of vitamin $\mathrm{K}$ at birth. Our results, however, suggested that vitamin $\mathrm{K}$ prophylaxis once or twice at birth was not sufficient completely to prevent vitamin $\mathrm{K}$ deficiency at 1 month.

We found 51 cases of vitamin K deficiency, nine of whom had very high concentrations of PIVKA-II on the blood spot test or plasma assay. Seven of these cases had critically low clotting activity based on the normotest. Of the nine cases with severe vitamin $\mathrm{K}$ deficiency, one had congenital bile duct atresia and two mildly raised serum transaminase activities, whereas the remaining six cases had no predisposing factors such as chronic diarrhoea, malnutrition, or broad range antibiotics. Vitamin K dependent coagulant activities promptly improved and the plasma PIVKA-II concentration decreased gradually in all cases on an injection of vitamin $\mathrm{K}$. Only one of these cases had intracranial haemorrhage. It can be speculated that the monitoring system and treatment was effective.

Over three years (1979-81) 16 cases of late onset vitamin $\mathrm{K}$ deficiency were reported in the area where this study was performed ${ }^{14}$ and almost all these infants did not receive vitamin $\mathrm{K}$ prophylaxis.
During the period of this study ( 21 months), based in the same area, only three cases of vitamin $\mathrm{K}$ deficiency were observed. In one of these cases the deficiency occurred at 28 days of age-that is, before the PIVKA-II concentration was measuredand was therefore not included in this report. The others were case 2 in Table 2 and the case of congenital bile duct atresia mentioned above.

A recent survey by the study group of the Ministry of Health and Walfare of Japan indicated an incidence of three in 1000 infants with critical normotest activities (below 20\%) for 1 month old breast fed infants who did not receive vitamin $\mathrm{K}$ prophylaxis. The study group speculated that one in four or five infants with normotest values $<20 \%$ might develop a bleeding disorder due to vitamin $\mathrm{K}$ deficiency as the incidence of the disease was 1 in 1700 in breast fed infants. ${ }^{1}$ The incidence of critical normotest activities is close to the incidence of infants with high PIVKA-II concentrations (above $20 \mathrm{AU} / \mathrm{ml}$ ).

We speculate that some infants with high PIVKAII concentrations might have suffered from the disease if they had not received vitamin $K$. The decrease in the number of patients seemed to be due to the prophylactic administration of vitamin $\mathrm{K}$, which was performed for roughly $60 \%$ of the infants in this area, or the selective administration of vitamin $\mathrm{K}$ to infants with high PIVKA-II concentrations found by screening, or both.

Because screening for vitamin $\mathrm{K}$ deficiency by means of this method costs much more than the routine administration of vitamin $\mathrm{K}$, both economically and socially, we hope to prevent the disease by means of prophylactic administration of the vitamin to all newborn babies. If the oral administration of vitamin $\mathrm{K}$ is continued as a routine method of preventing the disease the optimal dose of the vitamin needs to be determined.

This work was supported by a grant from Eisai Co Ltd.

\section{References}

1 Nakayama K. The etiology of vitamin deficiency in infants. Perinatal Medicine 1982;12:1029-34.

2 Motohara K. Matsukura M. Matsuda I, et al. Severe vitamin K deficiency in breast-fed infants. J Pediatr 1984:105:943-5.

${ }^{3}$ Lane PA. Hathaway WE, Githens JH, Rosenberg DA. Fatal intracranial hemorrhage in a normal infant secondary to vitamin K deficiency. Pediatrics 1983;72:562-4

+ Ware S, Mills M. Vitamin K deficiency causing infantile intracranial hacmorrhage after the neonatal period. Lancet 1983;i:1439-40.

5 Lovric VA, Jones RF. The haemorrhagic syndrome of early childhood. Australasian Annals of Medicine 1967;16:173-5.

${ }^{6}$ Bhanchet P. Tuchinda S, Hathirat P. Visudhiphan P. Bhamaraphavati $N$, Bukkavesa $S$. A blecding syndrome in infants due to acquired prothrombin complex efficiency: a survey of 93 affected infants. Clin Pediatr 1977;16:992-8. 
7 Chaou WT, Chou ML, Eitzman DV. Intracranial hemorrhage and vitamin $\mathrm{K}$ deficiency in early infancy. $J$ Pediatr 1984;105:880-4.

$\therefore$ Verity CM, Carswell F, Scott GL. Vitamin K deficiency causing infantile intracranial haemorrhage after the neonatal period. Lancet 1982;i:1439.

9 American Academy of Pediatrics. Report of committee on nutrition, vitamin $\mathrm{K}$ compounds and the water-soluble analogues. Use in therapy and prophylaxis in pediatrics. Pediatrics 1961:28:501-7.

10 Olson RE. The function and metabolism of vitamin K. Ann Rev Nutr 1984;4:281-337.

"Motohara K, Kuroki Y, Kan H, Endo F, Matsuda I. Detection of vitamin $\mathrm{K}$ deficiency by use of an enzyme-linked immunosorbent assay for circulating abnormal prothrombin. Pediatr Res 1985;19:354-7.

12 Motohara K, Endo F, Matsuda I. Vitamin K deficiency in breast-fed infants at one month of age. J Pediatr Gastroenterol Nutr. (In press.)

13 Owren PA, Strandi OK. Normotest. Farmakoterapi 1969;25: 14-26.

${ }^{14}$ Motohara K, Matsukura M, Nishiyama S, et al. Vitamin K deficiency in young infants-studies on prophylactic vitamin $\mathrm{K}$ administration and its pathogenesis. Japanese Journal of Pediatric Society 1983;87:1650-6.

is Shearer MJ, Rahim S, Barkhan P, Stimmler L. Plasma vitamin $K_{1}$ in mothers and their newborn babies. Lancet 1982;ii:460-3.
${ }^{16}$ Hemker HC, Muller AD, Loeliger EA. Two types of prothrombin in vitamin K deficiency. Thrombosis et Diathesis Haemorrhagica 1970;26:633-7.

17 Ganrot PO, Nilehn JE. Plasma prothrombin during treatment with dicumarol. II. Demonstration of an abnormal prothrombin fraction. Scand J Clin Lab Invest 1968;22:23-8.

18 Corrigan JJJR. Vitamin K dependent proteins. Adv Pediatr 1981;28:57-70.

${ }^{19}$ Motohara K, Endo F, Matsuda I. Effect of vitamin K administration on acarboxyprothrombin (PIVKA-II) levels in newborns. Lancet 1985;ii:242-4.

${ }^{20}$ McNinch AW, Upton C, Samuels M, et al. Plasma concentrations after oral or intramuscular vitamin $\mathrm{K}_{1}$ in neonates. Arch Dis Child 1985;60:814-8.

${ }^{21}$ Sann L, Leclercq M, Gillaumont M, Trouyez R, Bethenod M, Bourgeay-Causse $M$. Serum vitamin $K$ concentrations after oral administration of vitamin $\mathrm{K}$, in low birth weight infants. $J$ Pediatr 1985;107:608-11.

22 Aballi AJ. Vitamin K deficiency. Pediatrics 1985;75:372-3.

Correspondence to Dr K Motohara, Sumoto Amakusa, Kumamoto 861-63, Japan.

Received 27 August 1986 